\title{
Hydration of Potassiated Amino Acids in the Gas Phase
}

\author{
Henryk Wincel \\ Institute of Physical Chemistry, Polish Academy of Sciences, Warsaw, Poland
}

The thermochemistry of stepwise hydration of several potassiated amino acids was studied by measuring the gas-phase equilibria, $\mathrm{AAK}^{+}\left(\mathrm{H}_{2} \mathrm{O}\right)_{n-1}+\mathrm{H}_{2} \mathrm{O}=\mathrm{AAK}^{+}\left(\mathrm{H}_{2} \mathrm{O}\right)_{n}(\mathrm{AA}=\mathrm{Gly}$, AL, Val, Met, Pro, and Phe), using a high-pressure mass spectrometer. The $\mathrm{AAK}^{+}$ions were obtained by electrospray and the equilibrium constants $K_{n-1, n}$ were measured in a pulsed reaction chamber at 10 mbar bath gas, $\mathrm{N}_{2}$, containing a known partial pressure of water vapor. Determination of the equilibrium constants at different temperatures was used to obtain the $\Delta H_{n}^{o}, \Delta S_{n}^{o}$ and $\Delta G_{n}^{o}$ values. The results indicate that the water binding energy in $\operatorname{AAK}^{+}\left(\mathrm{H}_{2} \mathrm{O}\right)$ decreases as the $\mathrm{K}^{+}$affinity to AA increases. This trend in binding energies is explained in terms of changes in the side-chain substituent, which delocalize the positive charge from $\mathrm{K}^{+}$ to $\mathrm{AA}$ in $\mathrm{AAK}^{+}$complexes, varying the $\mathrm{AAK}^{+}-\mathrm{H}_{2} \mathrm{O}$ electrostatic interaction. (J Am Soc Mass Spectrom 2007, 18, 2083-2089) (C) 2007 American Society for Mass Spectrometry

$\mathrm{K}$ and $\mathrm{Na}^{+}$ions are the most abundant metal cations in living systems. They play an important role in several biochemical functions such as enzyme regulation, transfer of metal ions from intracellular to extracellular environments, electrical excitability of nerves, stabilization of DNA structures and so on [1]. Therefore, the interaction between alkali metal cations and various amino acids (AAs) has attracted considerable attention, and many experimental and theoretical studies have been conducted [2-20]. These studies show that $\mathrm{K}^{+}$binds to AAs quite differently than $\mathrm{Na}^{+}$. For example, in the case of aliphatic AAs such as glycine (Gly), alanine (Ala), and valine (Val), the $\mathrm{Na}^{+}$ion is coordinated to nitrogen and carbonyl oxygen ( $\mathrm{NO}$ coordination) in the lowest energy conformers, while $\mathrm{K}^{+}$prefers to bind to the carbonyl and hydroxyl oxygen atoms of the charge-solvated form (OO coordination) $[6,8,10,16]$. In proline (Pro), phenylalanine (Phe), and cysteine (Cys), the modes of $\mathrm{K}^{+}$binding are similar to those of the corresponding $\mathrm{Na}^{+}$complexes $[3-5,12,20]$.

Molecular dynamics simulations of a bacterial potassium ion channel reveal a significant selectivity filter for $\mathrm{K}^{+}$compared with $\mathrm{Na}^{+}$ions $[21,22]$. The different hydration state of $\mathrm{Na}^{+}$and $\mathrm{K}^{+}$in the channel inner pore is postulated to be a basic factor determining ionic selectivity [23, 24]. Investigations into the relative energetics of noncovalent interactions between single amino acids, metal ions and water molecules could provide important information to explain ion channel function at a molecular level. Despite the considerable amount of

Address reprint requests to Professor Henryk Wincel, Institute of Physical Chemistry, Polish Academy of Sciences, Kasprzaka 44/52, 01-224 Warsaw, Poland. E-mail: wincel@ichf.edu.pl experimental and theoretical studies that have been conducted on the binding of $\mathrm{Na}^{+}$and $\mathrm{K}^{+}$to amino acids, little data are available on the interactions of water molecules with metal ion/amino acid complexes. Because metal ions and biomolecules are normally surrounded by water in living systems, these interactions are of significant importance in understanding biological systems. Williams and coworkers [8, 25-31] studied the modes of metal ion and water binding in hydrated complexes of alkali metal cationized valine, glutamine, lysine, and $\alpha$-methyl-proline using both blackbody infrared radiative dissociation (BIRD) experiments and theory. Armentrout et al. investigated the sequential bond energies of water to sodiated glycine [32] and proline [33] by threshold collision-induced dissociation (TCID) experiments, as well as by accurate theoretical calculations. Recently, Kamariotis et al. [34] conducted infrared (IR) spectroscopy on hydration of lithiated valine, correlating the results with their calculations. The effect of metal ion and water coordination on the structures of hydrated metal ion/glycine complexes have been studied theoretically $[35,36]$.

In the present paper, the hydration energies and entropies for a number of potassiated amino acids, $\mathrm{AAK}^{+}$, were obtained from high-pressure mass spectrometry equilibria measurements in the gas phase. This work is a continuation of previous studies on the interaction of water molecules with protonated $[37,38]$ and sodiated [39] amino acids.

\section{Experimental}

The experiments were performed with a high-pressure mass spectrometer (HPMS) using a pulsed ion-beam 
ESI ion source, which has been previously described in detail [37]. Briefly, potassiated amino acids were obtained by electrospray from a silica capillary $(15 \mu \mathrm{m}$ i.d., $150 \mu \mathrm{m}$ o.d.). The solution containing $2.0 \mathrm{mM} \mathrm{AA}$ and $2.0 \mathrm{mM} \mathrm{KI}$ in methanol was supplied to the capillary by a syringe pump at a rate of $0.8 \mu \mathrm{L} / \mathrm{min}$. The clustered ions were desolvated by a dry nitrogen gas counter current and in a heated pressure reducing capillary through which they were introduced into the forechamber, and then deflected toward a 3-mm orifice in the interface plate leading to the reaction chamber (RC). Ions drifting across the $\mathrm{RC}$ toward the exit slit under the influence of a weak electric field $(2 \mathrm{~V} / \mathrm{cm}$ at $10 \mathrm{mbar})$ were hydrated and reached equilibrium before being sampled to the mass analysis section of the mass spectrometer.

Mass spectra were registered with continuous ion sampling, while for equilibrium determination the ion beam was injected into the RC in a pulsing mode by applying short pulses $(+34 \mathrm{~V}, 60 \mu \mathrm{s})$ to the deflection electrode with repetition of $1 \mathrm{~ms}$. The latter mode of operation allows for measurements of the arrival time distribution (ATD) of the ions across the RC.

The reagent gas mixture consisting of pure $\mathrm{N}_{2}$ as the carrier gas at about 10 mbar and a known partial pressure of water vapor (0.02 to $0.25 \mathrm{mbar}$ ) was supplied to the RC via the heated reactant gas inlet (RGI) at a flow rate of $\sim 100 \mathrm{~mL} / \mathrm{min}$. The pressure was measured with an MKS capacitance manometer attached near the inlet of the RGI. The amount of water introduced into the $\mathrm{N}_{2}$ gas flow was kept constant throughout the temperature-dependent measurements of the equilibrium constants. Water concentrations were controlled continuously with a calibrated temperature and humidity transmitter (Delta OHM, Type DO 9861T, Caselle di Selvazzano, Italy) inserted into the carrier gas flow line. The RC temperature was monitored by an iron-constantan thermocouple, which was embedded close to the ion exit slit; the temperature can be varied from ambient to $300^{\circ} \mathrm{C}$ by electrical heaters.

\section{Chemicals}

The amino acids were obtained from Aldrich Chemical Co. (Steinheim, Germany) KI and $\mathrm{CH}_{3} \mathrm{OH}$ was purchased from Chempur (Poland). The water was deionized with a Millipore purifier, type Elix 5 (Vienna, Austria).

\section{Results and Discussion}

\section{Determination of the Thermodynamic Data}

The thermochemical properties of the hydration of $\mathrm{AAK}^{+}$were obtained by measuring the equilibrium constants, $K_{n-1, n}$, as a function of temperature for each $(n-1, n)$ reaction, eq1

$$
\operatorname{AAK}^{+}\left(\mathrm{H}_{2} \mathrm{O}\right)_{n-1}+\mathrm{H}_{2} \mathrm{O} \Leftrightarrow \operatorname{AAK}^{+}\left(\mathrm{H}_{2} \mathrm{O}\right)_{n}
$$

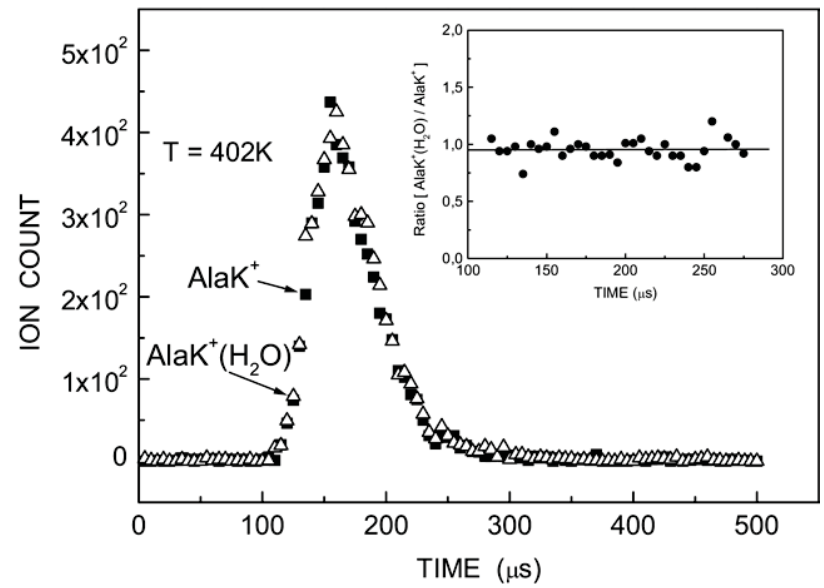

Figure 1. Arrival time distributions of the reactant, $\mathrm{AlaK}^{+}$, and product, $\mathrm{AlaK}^{+}\left(\mathrm{H}_{2} \mathrm{O}\right)$, ions. The inset shows the ion intensity ratio of $\left[\mathrm{AlaK}^{+}\left(\mathrm{H}_{2} \mathrm{O}\right) / \mathrm{AlaK}^{+}\right]$as a function of ion residence time.

For a standard state pressure of 1000 mbar the equilibrium constant is given by

$$
K_{n-1, n}=\left(I_{n} \times 1000 / I_{n-1} \times P\right)
$$

where $I_{n}$ and $I_{n-}$ are the recorded ATD peak areas of the corresponding ions and $P$ is the known partial pressure of water (in mbar). Equilibrium attainment was checked by comparing the ATDs of the reactant and product ions, and their ATDs were to be the same (except for the scaling factor of the peak amplitude). A typical example is shown in Figure 1 for $\mathrm{AlaK}^{+}$and $\operatorname{AlaK}^{+}\left(\mathrm{H}_{2} \mathrm{O}\right)$. The inset of the figure shows that within the error limits and the limits of statistical noise, the ratio $\left[\mathrm{AlaK}^{+}\left(\mathrm{H}_{2} \mathrm{O}\right) /\right.$ $\left.\mathrm{AlaK}^{+}\right]$remains essentially constant, suggesting the attainment of equilibrium for the system under the present experimental conditions. Once the equilibrium constants at several temperatures are determined, the values for the enthalpy, $\Delta H_{n}^{v}$, and entropy, $\Delta S_{n}^{o}$, changes for the reaction (eq 1) can be evaluated from plots of the logarithm of $\ln K_{n-1, n}$ against reciprocal temperature as defined by the van't Hoff equation,

$$
\text { In } K_{n-1, n}=\left(\triangle S_{n}^{0} / R\right)-\left(\triangle H_{n}^{0} / R T\right)
$$

As an example, the van't Hoff plots of the equilibrium constants for the systems studied are shown in Figure 2. No bending in the van't Hoff plots was observed through the present experiments. The weighted least-squares fitting procedure was used to obtain the slopes and intercepts of each line. The slopes determine the enthalpy change $\left(\Delta H_{n}^{v}\right)$ and the intercepts give the corresponding $\Delta S_{n}^{o}$ values. The reported $\Delta H_{n}^{o}$ and $\Delta S_{n}^{o}$ values are the averages of at least three measurements. The error limits show the statistical fluctuations; the absolute error could be considerably larger. The free-energy $\left(\Delta G_{n}^{o}\right)$ was obtained from $\Delta G_{n}^{o}=$ $\Delta H_{n}^{0}-T \Delta S_{n}^{o}$. The thermochemical properties thus obtained are summarized in Table 1, together with the 

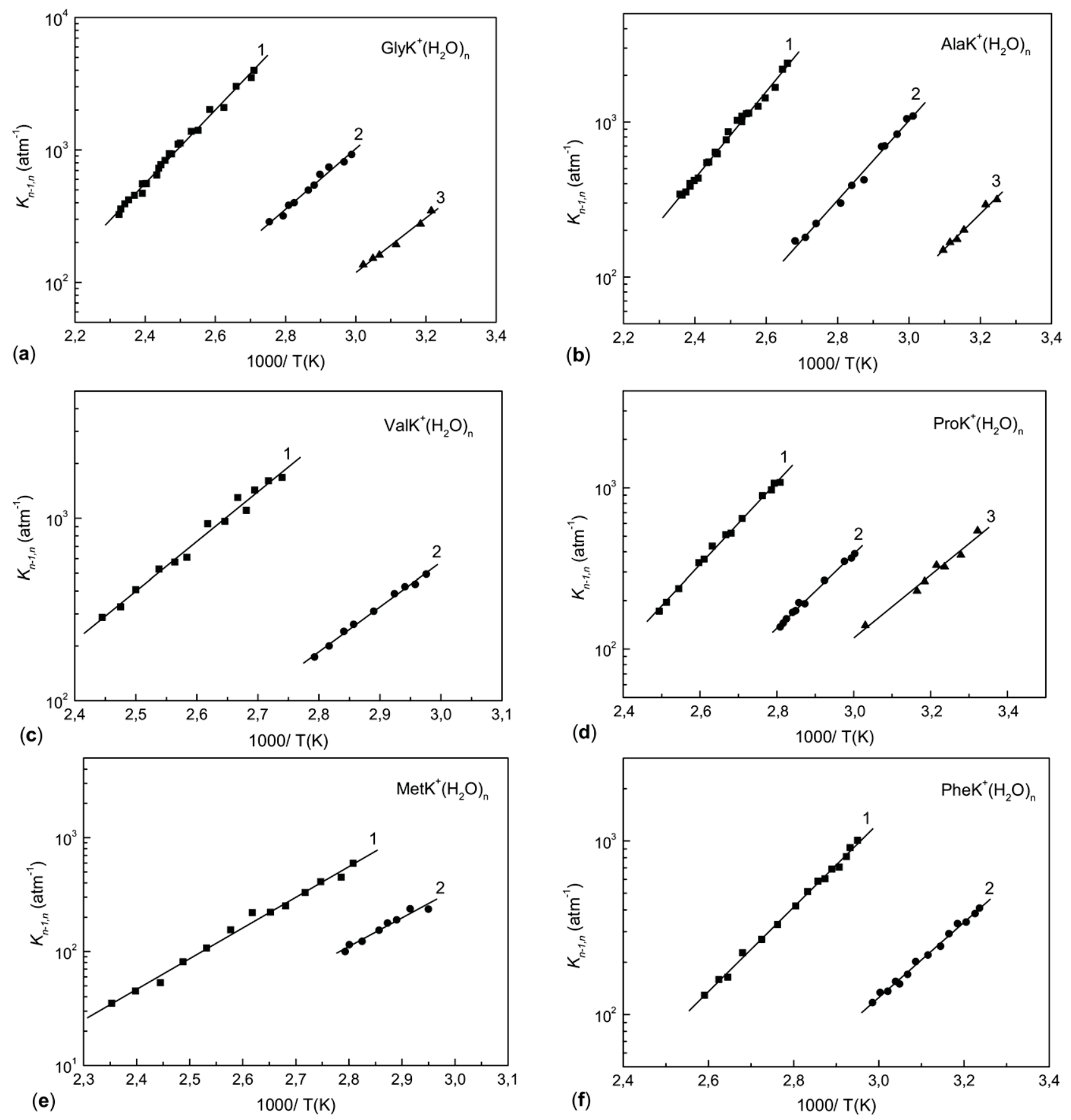

Figure 2. van't Hoff plots of equilibrium constants for the gas-phase reactions $\mathrm{AAK}^{+}\left(\mathrm{H}_{2} \mathrm{O}\right)_{n-1}+\mathrm{H}_{2} \mathrm{O}=$ $\mathrm{AAK}^{+}\left(\mathrm{H}_{2} \mathrm{O}\right)_{n}$, where AA equals (a) Gly; (b) Ala; (c) Val; (d) Pro; (e) Met; (f) Phe. The numbers shown in the figures correspond to the value of $n$.

literature results. The data for small $n$ are given in this table, since determination of the hydration enthalpies for higher hydration steps requires temperatures below room temperature, which are not accessible with the present reaction chamber.

An additional set of experiments was conducted to provide a basis for comparison with the data obtained in the other laboratory. Table 1 shows that the present thermochemical values obtained for the reaction

$$
\mathrm{K}^{+}\left(\mathrm{H}_{2} \mathrm{O}\right)_{n-1}+\mathrm{H}_{2} \mathrm{O} \Leftrightarrow \mathrm{K}^{+}\left(\mathrm{H}_{2} \mathrm{O}\right)_{n}
$$

with $n=2$ and 3 agreeing reasonably well with those reported in reference [40].

\section{Comparison with Other Complexes}

As expected, the water binding energies (BEs) to $\mathrm{AAK}^{+}$ are smaller than those for $\mathrm{AANa}^{+}$of the analogous 
Table 1. Experimental enthalpies, entropies, and free energies for the sequential hydration of $\mathrm{K}^{+}$and potassiated amino acids ${ }^{\mathrm{a}}$. Values from the literature (in italics) are included for comparison

\begin{tabular}{|c|c|c|c|c|c|}
\hline Ion & $n$ & $-\Delta H_{n}^{\circ}(\mathrm{kcal} / \mathrm{mol})$ & $-\Delta S_{n}^{\circ}(\mathrm{cal} / \mathrm{mol} \mathrm{K})$ & $-\Delta G_{n}^{\mathrm{o}}(\mathrm{kcal} / \mathrm{mol})^{\mathrm{b}}$ & Ref. \\
\hline \multirow[t]{4}{*}{$\mathrm{K}^{+}$} & 2 & $15.5(0.6)$ & $22.8(1.6)$ & $8.7(1.1)$ & \\
\hline & & $16.1^{\mathrm{c}}$ & $24.2^{\mathrm{C}}$ & $8.9^{c}$ & [40] \\
\hline & 3 & $12.6(0.6)$ & $21.6(1.6)$ & $6.2(1.1)$ & \\
\hline & & $13.2^{\mathrm{c}}$ & $23^{c}$ & $6.3^{c}$ & [40] \\
\hline \multirow[t]{3}{*}{$\mathrm{GlyK}^{+}$} & 1 & $13.3(0.5)$ & $19.3(1.1)$ & $7.6(0.8)$ & \\
\hline & 2 & $11.2(0.6)$ & $19.8(1.9)$ & $5.3(1.1)$ & \\
\hline & 3 & $9.5(0.8)$ & $18.9(1.8)$ & $3.9(1.3)$ & \\
\hline \multirow[t]{3}{*}{$\mathrm{AlaK}^{+}$} & 1 & $13.0(0.6)$ & $18.8(1.4)$ & $7.4(1.0)$ & \\
\hline & 2 & $11.0(0.4)$ & $19.4(1.1)$ & $5.2(0.7)$ & \\
\hline & 3 & $9.8(0.6)$ & $20.4(2.0)$ & $3.8(1.2)$ & \\
\hline \multirow[t]{4}{*}{ ValK $^{+}$} & 1 & $12.6(0.6)$ & $19.4(1.2)$ & $6.9(0.9)$ & \\
\hline & & $(13.6 ; 16.1)^{d}$ & & & 7] \\
\hline & 2 & $11.2(0.6)$ & $21.2(2.0)$ & $4.9(1.2)$ & \\
\hline & & $7.5^{\mathrm{e}}$ & & & [25] \\
\hline \multirow[t]{2}{*}{ MetK $^{+}$} & 1 & $12.3(0.6)$ & $22.5(1.9)$ & $5.6(1.1)$ & \\
\hline & 2 & $10.8(1.0)$ & $20.8(2.6)$ & $4.6(1.8)$ & \\
\hline \multirow[t]{3}{*}{ ProK $^{+}$} & 1 & $11.9(0.2)$ & $19.4(0.4)$ & $6.2(0.3)$ & \\
\hline & 2 & $10.9(0.7)$ & $21.3(1.5)$ & $4.6(1.1)$ & \\
\hline & 3 & $9.0(0.6)$ & $17.4(2.0)$ & $3.8(1.2)$ & \\
\hline \multirow[t]{2}{*}{$\mathrm{PheK}^{+}$} & 1 & $11.7(0.5)$ & $20.7(1.5)$ & $5.6(0.9)$ & \\
\hline & 2 & $10.0(0.5)$ & $20.2(1.5)$ & $4.0(0.9)$ & \\
\hline
\end{tabular}

Standard pressure is 1000 mbar.

Earrors are listed in parenthesis.

${ }^{\mathrm{b}} \Delta G^{\mathrm{O}}$ at $298 \mathrm{~K}$

'Using high-pressure mass spectrometry [40].

${ }^{\mathrm{d} B i n d i n g ~ e n e r g i e s ~ c a l c u l a t e d ~ a t ~ t h e ~ B 3 L Y P / L A C V P ~}++{ }^{* *}$ level of theory for zwitterionic $(13.6 \mathrm{kcal} / \mathrm{mol})$ and nonzwitterionic $(16.1 \mathrm{kcal} / \mathrm{mol})$ structure of $\mathrm{ValK}^{+}\left(\mathrm{H}_{2} \mathrm{O}\right)$ [7].

eUsing blackbody infrared radiative dissociation [25].

systems. For comparison, the available experimental gas-phase bond enthalpies and free energies for monohydrated $\mathrm{AAM}^{+}, \mathrm{M}=\mathrm{Na}$ and $\mathrm{K}$ are given in Table 2 . These results can be easily understood when one considers that $\mathrm{H}_{2} \mathrm{O}$ in the $\mathrm{AAM}^{+}\left(\mathrm{H}_{2} \mathrm{O}\right)$ system interacts directly with the alkali metal cation, and the bonding is largely electrostatic. The stronger binding to $\mathrm{AANa}^{+}$ than $\mathrm{AAK}^{+}$is consistent with the larger radius, the longer bond distances, and the weaker electrostatic interactions for $\mathrm{K}^{+}$compared with $\mathrm{Na}^{+}$.

The data in Table 1 show a monotonic decrease in the water BEs $\left(-\Delta H_{n}^{o}\right)$ with sequential addition of water molecules to $\mathrm{AAK}^{+}$. Similar trends were observed upon sequential hydration of the analogous sodiated amino acids $[29,30,32,33,39]$. As an example, Figure 3 shows

Table 2. Enthalpy and free energy changes for the gas-phase hydration of the potassiated $\left(\mathrm{AAK}^{+}\right)$and sodiated $\left(\mathrm{AANa}^{+}\right)$ amino acids

\begin{tabular}{llllll}
\hline & \multicolumn{2}{c}{$-\Delta H_{1}^{o}(\mathrm{kcal} / \mathrm{mol})$} & & \multicolumn{2}{c}{$-\Delta G_{1}^{o}(\mathrm{kcal} / \mathrm{mol})$} \\
\cline { 2 - 3 } \cline { 5 - 6 } AA & AAK $^{+}$ & $\mathrm{AANa}^{+}$ & & $\mathrm{AAK}^{+}$ & $\mathrm{AANa}^{+}$ \\
\hline \hline Gly & 13.3 & $17.9^{\mathrm{a}}$ & & 7.6 & $11.2^{\mathrm{a}}$ \\
Val & 12.6 & $15.9^{\mathrm{b}}$ & & 6.9 & $9.7^{\mathrm{b}}$ \\
Pro & 11.9 & $14.5^{\mathrm{b}}, 15.8^{\mathrm{c}}$ & & 6.2 & $8.9^{\mathrm{b}}, 9.0^{\mathrm{c}}$ \\
Met & 12.3 & $13.7^{\mathrm{b}}$ & & 5.6 & $8.0^{\mathrm{b}}$ \\
Phe & 11.7 & $13.6^{\mathrm{b}}$ & & 5.6 & $7.9^{\mathrm{b}}$ \\
\hline
\end{tabular}

aUsing threshold collision-induced dissociation [32].

bUsing pulsed ion-beam high-pressure mass spectrometry [39].

'Using threshold collision-induced dissociation [33]. the behavior of the hydration free energies $\left(-\Delta G_{n}^{o}\right)$ as a function of $n$ for $\operatorname{ProK}^{+}\left(\mathrm{H}_{2} \mathrm{O}\right)_{n}$ and $\operatorname{ProNa}^{+}\left(\mathrm{H}_{2} \mathrm{O}\right)_{n}$. For comparison, the inset shows an analogous plot for the $\mathrm{K}^{+}\left(\mathrm{H}_{2} \mathrm{O}\right)_{n}$ and $\mathrm{Na}^{+}\left(\mathrm{H}_{2} \mathrm{O}\right)_{n}$ systems. The observed decrease in binding energies of water can be rationalized by a partial delocalization of the charge on the water binding site(s) and increasing repulsive interactions

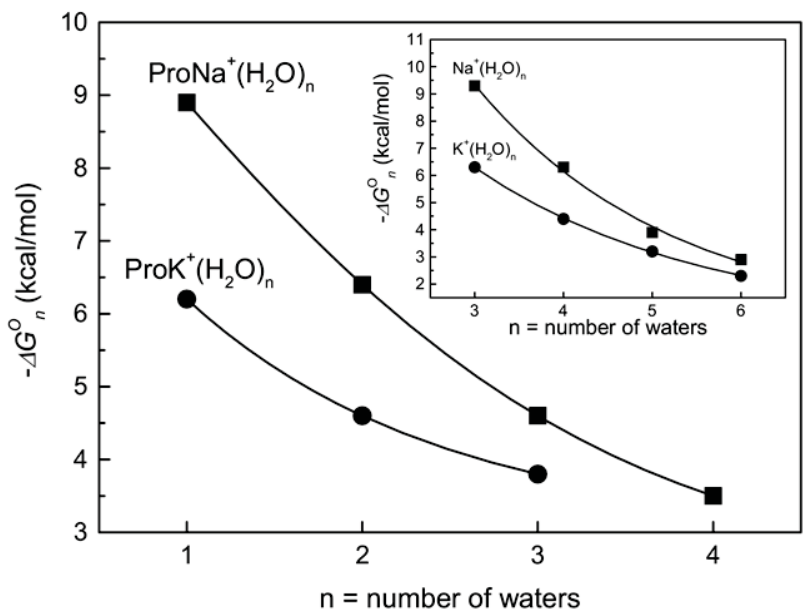

Figure 3. Comparison of the $n$ dependence of the hydration free energies $\left(-\Delta G_{n}^{\mathrm{O}}\right)$ at $298 \mathrm{~K}$ for the $\operatorname{ProK}^{+}\left(\mathrm{H}_{2} \mathrm{O}\right)_{n}$ and $\operatorname{ProNa}^{+}\left(\mathrm{H}_{2} \mathrm{O}\right)_{n}$ complexes. The inset shows plots of the $-\Delta G_{n}^{\mathrm{O}}$ values vs. $n$. The $-\Delta G_{n}^{\mathrm{O}}$ values for $\operatorname{ProNa}^{+}\left(\mathrm{H}_{2} \mathrm{O}\right)_{n}$, reference [39]; $\mathrm{K}^{+}\left(\mathrm{H}_{2} \mathrm{O}\right)_{n}$ and $\mathrm{Na}^{+}\left(\mathrm{H}_{2} \mathrm{O}\right)_{n}$, reference [40]. 
between ligated water molecules with successive addition to AAK.

\section{Solvation Effect and Water Binding Energies}

The water binding ratio $\left(\mathrm{GlyK}^{+}-\mathrm{H}_{2} \mathrm{O}\right) /\left(\mathrm{GlyNa}^{+}-\right.$ $\mathrm{H}_{2} \mathrm{O}$ ) is identical to that obtained [16] for (Gly $\left.\mathrm{K}^{+}\right) /\left(\mathrm{Gly}-\mathrm{Na}^{+}\right), 0.74$. The BEs of the first $(13.3 \pm 0.5$ $\mathrm{kcal} / \mathrm{mol})$ and second $(11.2 \pm 0.5 \mathrm{kcal} / \mathrm{mol})$ water molecules in $\mathrm{GlyK}^{+}\left(\mathrm{H}_{2} \mathrm{O}\right)_{n}$ are very close to those of the third $(13.2 \mathrm{kcal} / \mathrm{mol})$ and fourth $(11.8 \mathrm{kcal} / \mathrm{mol})$ water to $\mathrm{K}^{+}$in the $\mathrm{K}^{+}\left(\mathrm{H}_{2} \mathrm{O}\right)_{n}$ system [40]. Similar results have also been obtained by Armentrout and coworkers [32] for $\mathrm{GlyNa}^{+}\left(\mathrm{H}_{2} \mathrm{O}\right)_{n}$. They found using the TCID method that the BEs of the first $(17.9 \pm 1.2 \mathrm{kcal} / \mathrm{mol})$ and second $(13.1 \pm 1.7 \mathrm{kcal} / \mathrm{mol})$ water molecules in $\mathrm{GlyNa}^{+}\left(\mathrm{H}_{2} \mathrm{O}\right)_{n}$ are close to those of the third $(16.7 \pm 1.4 \mathrm{kcal} / \mathrm{mol})$ and fourth $(13.1 \pm 1.4 \mathrm{kcal} / \mathrm{mol})$ water to $\mathrm{Na}^{+}$in the $\mathrm{Na}^{+}\left(\mathrm{H}_{2} \mathrm{O}\right)_{n}$ cluster. These observations indicate that the solvation effect provided by glycine on both $\mathrm{Na}^{+}$ and $\mathrm{K}^{+}$is nearly equivalent to that of the first and second attached water molecules in the $\mathrm{Na}^{+}\left(\mathrm{H}_{2} \mathrm{O}\right)_{n}$ and $\mathrm{K}^{+}\left(\mathrm{H}_{2} \mathrm{O}\right)_{n}$ systems. As can be seen in Table 1 , the BEs of a water molecule in the $\mathrm{AAK}^{+}\left(\mathrm{H}_{2} \mathrm{O}\right)$ complexes follow the order $\mathrm{GlyK}^{+}>\mathrm{AlaK}^{+}>\mathrm{ValK}^{+}>\mathrm{MetK}^{+}>\mathrm{ProK}^{+}$ $>\mathrm{PheK}^{+}$. Although the differences in the measured $-\Delta H_{n}^{o}$ values are small and generally are within the range of experimental uncertainty, the general trend is evident. A plot of the binding energies in $\mathrm{AAK}^{+}\left(\mathrm{H}_{2} \mathrm{O}\right)_{n}=1,2$ vs. the corresponding $\mathrm{K}^{+}$ion affinities of AAs is shown in Figure 4 . The $\mathrm{K}^{+}$affinity values calculated by Tsang and coworkers [13] were used for this figure. Because in this work no value exists for the binding affinity of $\mathrm{K}^{+}$(Met), we take the experimental value of $33.9 \pm 2.6 \mathrm{kcal} / \mathrm{mol}$ from reference [41] determined by Armentrout and coworkers. The $\mathrm{K}^{+}$

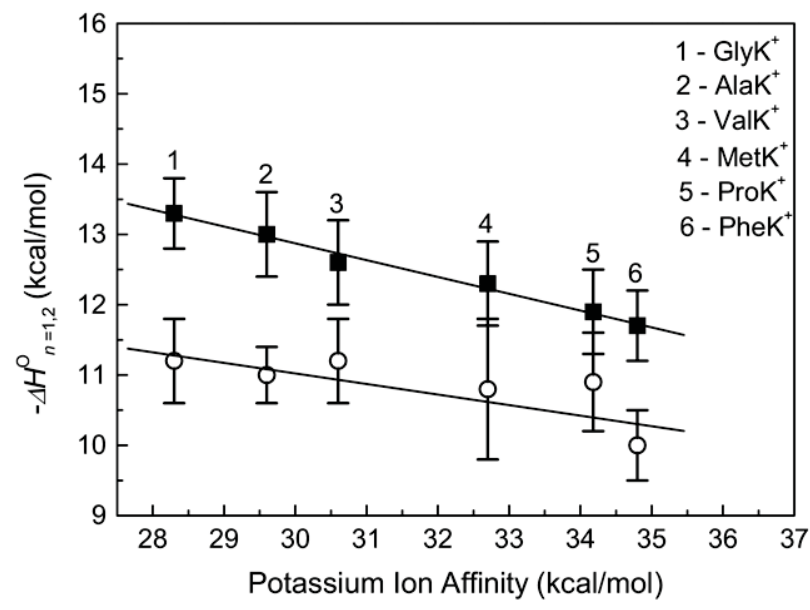

Figure 4. Plot of the binding energies $\left(-\Delta H_{n}^{\mathrm{O}}=1,2\right)$ for the first $(\square)$ and second $(O)$ water molecule in the $\mathrm{AAK}^{+}\left(\mathrm{H}_{2} \mathrm{O}\right)_{n}=1,2$ complexes vs. corresponding potassium ion affinity of amino acids (AAs). For Gly, Ala, Val, Pro, and Phe, the potassium ion affinity values are taken from reference [13].; for Met, from reference [41], see text. scale was anchored by $\mathrm{K}^{+}(\mathrm{Gly})$, taking the value reported by Armentrout et al. [16], $29.4 \mathrm{kcal} / \mathrm{mol}$, and $28.3 \mathrm{kcal} / \mathrm{mol}[13]$ as the reference value. This adjustment to the $\mathrm{K}^{+}$scale of reference [13] leads to the value of $32.8 \mathrm{kcal} / \mathrm{mol}$ for $\mathrm{K}^{+}$(Met), which was used for Figure 4 . As can be seen in this figure, a linear relationship between the measured $-\Delta H_{\mathrm{n}}^{\mathrm{o}}=1,2$ values and the potassium ion affinities is found. The correlation coefficients for the binding of the first and second water molecules are 0.99 and 0.83 , respectively. The $-\Delta H_{2}^{\mathrm{O}}$ values show a significantly larger deviations from the straight line plot than these of $-\Delta H_{1}^{\mathrm{O}}$. Now, it is not clear whether the observed deviations for $-\Delta H_{2}^{\mathrm{O}}$ are due to larger experimental errors or due a special intrinsic difference in the binding of the second water molecule in the $\mathrm{AAK}^{+}\left(\mathrm{H}_{2} \mathrm{O}\right)_{2}$ complexes. A very good linear correlation between the measured $-\Delta H_{1}^{\mathrm{O}}$ values and the $\mathrm{K}^{+}$affinities of AAs, Figure 4, can be explained as being a consequence of direct interaction of the first water molecule with the $\mathrm{K}^{+}$ion of $\mathrm{AAK}^{+}\left(\mathrm{H}_{2} \mathrm{O}\right)$ and the electrostatic nature of the $\mathrm{AAK}^{+}-\mathrm{H}_{2} \mathrm{O}$ binding. The net positive charge retained on the metal ion in $\mathrm{AAK}^{+}$ is expected to depend on the electron withdrawing effect of AA, determining the magnitude of the $\mathrm{K}^{+}$ affinity values to AAs. The charge density on the metal ion in $\mathrm{AAK}^{+}\left(\mathrm{H}_{2} \mathrm{O}\right)$ should decrease as the metal ion affinity of AA increases. The effect of the side chain illustrated here by a decrease in the water binding energies in $\mathrm{AAK}^{+}\left(\mathrm{H}_{2} \mathrm{O}\right)_{n}=1,2$ and previously [39] for $\mathrm{AANa}^{+}\left(\mathrm{H}_{2} \mathrm{O}\right)_{n}=1,2$ with increasing $\mathrm{K}^{+}$and $\mathrm{Na}^{+}$affinities to AA, respectively, is in line with observations [4, 14,18 ] that the binding of $\mathrm{K}^{+}$and $\mathrm{Na}^{+}$to amino acids is dominated by the interaction with the amino acid backbone and enhanced by interaction with the sidechain substituent. The binding enhancement effect of the phenyl substituent is manifested by the difference in the $\mathrm{K}^{+}$binding energies to Ala $(29.6 \mathrm{kcal} / \mathrm{mol} \mathrm{[13]} \mathrm{and}$ Phe $(34.8 \mathrm{kcal} / \mathrm{mol}$ [13], while the electron withdrawing effect is demonstrated by the observed difference between the hydration energies for $\mathrm{AlaK}^{+}$and $\mathrm{PheK}^{+}$, Table 1. Although this method of estimating influence is not fully satisfactory because the aliphatic portion is expected to contribute to the Ala $-\mathrm{K}^{+}$binding as well, the comparison shows the magnitude of the aromatic side-chain substituent effects on the enhancement in the AA $-\mathrm{K}^{+}$binding $(\sim 17 \%)$ and weakening ( $\left.11 \%\right)$ of the $\mathrm{AAK}^{+}-\mathrm{H}_{2} \mathrm{O}$ interaction.

\section{Comparison with Other Results}

The literature provides water binding energies only for $\mathrm{ValK}^{+}\left(\mathrm{H}_{2} \mathrm{O}\right)_{n=1,2}$ systems $[7,25]$. Williams and coworkers [7] showed, based on the BIRD technique, that the $\mathrm{K}^{+}$ion in the $\mathrm{ValK}^{+}\left(\mathrm{H}_{2} \mathrm{O}\right)$ complex is OO-coordinated. However, from these experiments they were unable to distinguish whether the valine in this system was nonzwitterionic 1, or zwitterionic 2, in form.

The binding energies of water calculated by these authors at the B3LYP/LACVP $++^{* *}$ level of theory 


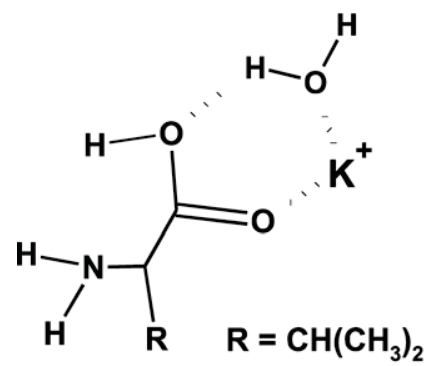

1

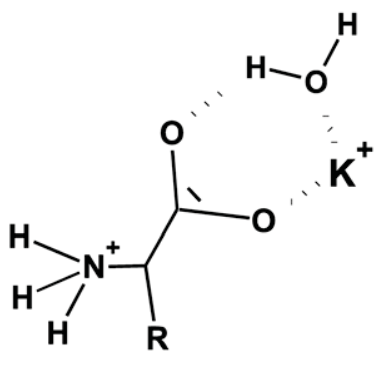

2

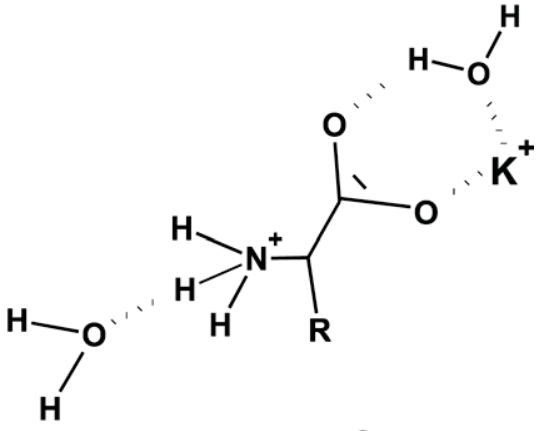

3 predict that the $\mathrm{ValK}^{+}-\mathrm{H}_{2} \mathrm{O}$ interaction in the nonzwitterionic form $(16.1 \mathrm{kcal} / \mathrm{mol})$ is stronger than in the zwitterionic one $(13.6 \mathrm{kcal} / \mathrm{mol})$. The latter value is close to that of $12.6 \pm 0.6 \mathrm{kcal} / \mathrm{mol}$ obtained in the present study, implying that the valine in $\operatorname{ValK}^{+}\left(\mathrm{H}_{2} \mathrm{O}\right)$ adopts a zwitterionic form, 2. The barrier between Structure $\mathbf{1}$ and Structure $\mathbf{2}$ is expected to be small compared with that for water loss, and the energy gained upon the hydration of $\mathrm{ValK}^{+}(12.6 \mathrm{kcal} / \mathrm{mol})$ is most probably sufficient for the interconversion $\mathbf{1} \rightarrow \mathbf{2}$, which simply involves the migration of a proton across the hydrogen bond from the hydroxyl oxygen to the amine group. Once Structure $\mathbf{2}$ is formed, it can be collisionally stabilized at the conditions maintained in the reaction chamber, and there is a low probability of back isomerization, $2 \rightarrow \mathbf{1}$. Thus, the $\mathrm{ValK}^{+}\left(\mathrm{H}_{2} \mathrm{O}\right)$ complex can further react as a zwitterionic Structure 2 . This conclusion is consistent with that deduced from the BIRD experiments of Williams and coworkers [25] that the valine in $\mathrm{ValK}^{+}\left(\mathrm{H}_{2} \mathrm{O}\right)_{2}$ is zwitterionic.

These authors also found that the second water molecule does not bind to the metal ion but rather interacts with the valine itself, and the most likely structure could be like 3 , in which the second water is hydrogen bonded to the $-\mathrm{NH}_{3}{ }^{+}$charge center. It should be noted that conformer 3 lies $3.1 \mathrm{kcal} / \mathrm{mol}$ higher in energy than the ground-state nonzwitterionic conformation [25], in which the second water molecule is bonded directly to $\mathrm{K}^{+}$of Structure $\mathbf{1}$.

Table 1 indicates that the binding energy of the second water in $\mathrm{ValK}^{+}\left(\mathrm{H}_{2} \mathrm{O}\right)_{2}$ obtained in the present experiments, $11.3 \pm 0.3 \mathrm{kcal} / \mathrm{mol}$, is significantly higher than that derived from the BIRD experiments [25], 7.5 $\mathrm{kcal} / \mathrm{mol}$. As noted by these authors, the latter value is almost certainly somewhat lower than the true one because of experimental difficulties with the measured dissociation kinetics of relatively weak potassiated clusters. It is worth mentioning that the water binding energies previously determined for $\mathrm{ValNa}^{+}\left(\mathrm{H}_{2} \mathrm{O}\right)_{n}=1,2$ and $\mathrm{GlnNa}^{+}\left(\mathrm{H}_{2} \mathrm{O}\right)_{n}=1,2$ from our high-pressure equilibrium measurements [39] are in excellent or good agreement with the experimental values obtained from the BIRD kinetics studies [25, 26, 29, 30].
As mentioned above, the lowest energy structures of aliphatic amino acids, $\mathrm{GlyK}^{+}$and $\mathrm{AlaK}^{+}$, are similar to that of $\mathrm{ValK}^{+}$, indicating the small influence, if any, of the aliphatic portions of the side chain on the structural arrangements in these complexes. The measured binding energy values of the first water molecule in these three complexes are similar (12.6 to $13.3 \mathrm{kcal} /$ $\mathrm{mol}$ ) and close to that calculated [7] for the zwitterionic form of $\mathrm{ValK}^{+}\left(\mathrm{H}_{2} \mathrm{O}\right)$, which is lower than that for the nonzwitterionic structure, Table 1. Therefore, although speculative, it seems very likely that GlyK $^{+}\left(\mathrm{H}_{2} \mathrm{O}\right)_{n=1,2}$ and $\mathrm{AlaK}^{+}\left(\mathrm{H}_{2} \mathrm{O}\right)_{n=1,2}$ formed in the present experiments have the structures analogous to those of $\mathrm{ValK}^{+}\left(\mathrm{H}_{2} \mathrm{O}\right)_{n=1,2}$.

\section{Conclusion}

The sequential binding energies of water to potassiated amino acids (glycine, alanine, valine, methionine, proline, and phenylalanine) were investigated by pulsed high-pressure mass spectrometry with electrospray ionization. Generally, the water binding energies to $\mathrm{AAK}^{+}$are weaker than to $\mathrm{AANa}^{+}$and, in both instances, decrease with the increasing number of water molecules. A good correlation was obtained between the binding energies of the water molecule in the $\mathrm{AAK}^{+}\left(\mathrm{H}_{2} \mathrm{O}\right)$ complexes and the corresponding potassium ion affinities to amino acids, showing the decrease in the $\mathrm{AAK}^{+}-\mathrm{H}_{2} \mathrm{O}$ binding energies with the increasing $\mathrm{AA}-\mathrm{K}^{+}$bond strength. This relationship is analogous to that reported previously for $\operatorname{AANa}^{+}\left(\mathrm{H}_{2} \mathrm{O}\right)_{n=1,2}$ complexes.

\section{Acknowledgments}

The authors gratefully acknowledge financial support (grant 3T09A02728) from the Ministry of Science and Higher Education, Poland.

\section{References}

1. Lippard, S. J.; Berg, J. M. Principles of Bioinorganic Chemistry; University Science Books: Mill Valley, CA, 1994; pp. 1-20.

2. Klassen, R. G.; Anderson, S. G.; Blades, A. T.; Kebarle, P. Reaction enthalpies for $\mathrm{M}^{+} \mathrm{L}=\mathrm{M}^{+}+\mathrm{L}$, where $\mathrm{M}^{+}=\mathrm{Na}^{+}$and $\mathrm{K}^{+}$and $\mathrm{L}=$ 
acetamide, N-methylacetamide, N,N-dimethylacetamide, glycine, and glycylglycine from determination of the collision-induced dissociation thresholds. J. Phys. Chem. 1996, 100, 14218-14227.

3. Hoyau, S.; Norrman, K.; McMahon, T. B.; Ohanessian, G. A quantitative basis for a scale of $\mathrm{Na}^{+}$affinities of organic and small biological molecules in the gas phase. I. Am. Chem. Soc. 1999, 121, 8864-8875.

4. Ryzhov, V.; Dunbar, R. C.; Cerda, B.; Wesdemiotis, C. Cation- $\pi$ effects in the complexation of $\mathrm{Na}^{+}$and $\mathrm{K}^{+}$with Phe, Tyr, and Trp in the gas phase. J. Am. Soc. Mass Spectrom. 2000, 11, 1037-1046.

5. Dunbar, R. C. Complexation of $\mathrm{Na}^{+}$and $\mathrm{K}^{+}$to aromatic amino acids: A density functional computational study of cation- $\pi$ interactions. J. Phys. Chem. A 2000, 104, 8067-8074.

6. Marino, T.; Russo, N.; Toscano, M. Potential energy surfaces for the gas-phase interaction between $\alpha$-alanine and alkali metal ions $\left(\mathrm{Li}^{+}\right.$, $\left.\mathrm{Na}^{+}, \mathrm{K}^{+}\right)$: A density functional study. Inorg. Chem. 2001, 40, 6439-6443.

7. Siu, F. M.; Ma, N. L.; Tsang, C. W. Cation $\pi$-interactions in sodiated complexes: Is in the charge-solvated or zwitterionic form? J. Am. Chem. Soc. 2001, 123, 3397-3398.

8. Jockusch, R. A.; Lemoff, A. S.; Williams, E. R. Effect of metal ion and water coordination on the structure of a gas-phase amino acid. J. Am. Chem. Soc. 2001, 123, 12255-12265.

9. Wong, C. H. S.; Siu F. M.; Ma, N. L.; Tsang, C. W. A theoretical study of potassium cation-glycine $\left(\mathrm{K}^{+}-\mathrm{Gly}\right)$ interactions. J. Mol. Struct. (Theochem.) 2002, 588, 9-16

10. Moision, R. M.; Armentrout, P. B. Experimental and theoretical dissection of sodium cation/glycine interactions. J. Phys. Chem. A 2002, 106, 10350-10362.

11. Talley, J. M.; Cerda, B. A.; Ohanessian, G.; Wesdemiotis, C. Alkali metal ion binding to amino acids versus their methyl esters: Affinity trends and structural changes in the gas phase. Chem. Eur. J. 2002, 8, 1377-1388.

12. Marino, T.; Russo, N.; Toscano, M. Interaction of $\mathrm{Li}^{+}, \mathrm{Na}^{+}$, and $\mathrm{K}^{+}$with the proline amino acid: Complexation modes, potential energy profiles, and metal ion affinities. J. Phys. Chem. B 2003, 107, 2588-2594.

13. Lau, J. K.-C.; Wong, C. H. S.; Ng, P. S.; Siu, F. M.; Ma, N. L.; Tsang, C. W. Absolute potassium cation affinities (PCAs) in the gas phase. Chem. Eur. J. 2003, 9, 3383-3396.

14. Kish, M. M.; Ohanessian, G.; Wesdemiotis C. The $\mathrm{Na}^{+}$affinities of $\alpha$-amino acids: Side-chain substituent effects. Int. J. Mass Spectrom. 2003, $227,509-524$

15. Gapeev, A.; Dunbar, R. C. $\mathrm{Na}^{+}$affinities of gas-phase amino acids by ligand exchange equilibrium. Int. J. Mass Spectrom. 2003, 228, 825-839.

16. Moision, R. M.; Armentrout, P. B. An experimental and theoretical dissection of potassium cation/glycine interactions. Phys. Chem., Chem. Phys. 2004, 6, 2588-2599.

17. Kapota, C.; Lemaire, J.; Maître, P.; Ohanessian G. Vibrational signature of charge solvation vs. salt bridge isomers of sodiated amino acids in the gas phase. J. Am. Chem. Soc. 2004, 126, 1836-1842.

18. Ruan, C.; Rodgers, M. T. Cation- $\pi$ interactions: Structures and energetics of complexation of $\mathrm{Na}^{+}$and $\mathrm{K}^{+}$with the aromatic amino acids, phenylalanine, tyrosine, and tryptophan. J. Am. Chem. Soc. 2004, 126, $14600-14610$.

19. Ruan, C.; Yang, Z.; Hallowita, N.; Rodgers, M. T. Cation- $\pi$ interactions with a model for the side chain of tryptophan: Structures and absolute binding energies of alkali metal cation-indole complexes. J. Phys. Chem. A 2005, 109, 11539-11550.

20. Moision, R. M.; Armentrout, P. B. The special five-membered ring of proline: An experimental and theoretical investigation of alkali metal cation interactions with proline and its four- and six-membered ring analogues. J. Phys. Chem. A 2006, 110, 3933-3946.
21. Guidoni, L.; Torre, V.; Carloni, P. Potassium and sodium binding to the outer mouth of the $\mathrm{K}^{+}$channel. Biochemistry 1999, 38, 8599-8604.

22. Shrivastava, I. H.; Tieleman, D. P.; Biggin, P. C.; Sansom, S. P. K ${ }^{+}$vs. $\mathrm{Na}^{+}$ions in a $\mathrm{K}$ channel selectivity filter: A simulation study. Biophys. J. 2002, 83, 633-645.

23. Laio, A.; Torre, V. Physical origin of selectivity in ionic channels of biological membranes. Biophys. J. 1999, 76, 129-148.

24. Gamel, K.; Torre, V. The interaction of $\mathrm{Na}^{+}$and $\mathrm{K}^{+}$in the pore of cyclic nucleotide-gated channels. Biophys. J. 2000, 79, 2475-2493.

25. Jockusch, R. A.; Lemoff, A. S.; Williams, E. R. Hydration of valine-cation complexes in the gas phase: On the number of water molecules necessary to form a zwitterion. J. Phys. Chem. A 2001, 105, 10929-10942.

26. Lemoff, A. S.; Bush, M. F.; Williams, E. R. Binding energies of water to sodiated valine and structural isomers in the gas phase: The effect of proton affinity on zwitterion stability. J. Am. Chem. Soc. 2003, 125 $13576-13584$

27. Lemoff, A. S.; Williams, E. R. Binding energies of water to lithiated valine: Formation of solution-phase structure in vacuo. J. Am. Soc. Mass Spectrom. 2004, 15, 1014-1024.

28. Lemoff, A. S.; Bush, M. F.; Williams, E. R. Structures of cationized proline analogues: Evidence for the zwitterionic form. J. Phys. Chem. A 2005, 109, 1903-1910.

29. Lemoff, A. S.; Bush, M. F.; Wu, C.-C.; Williams, E. R. Structures and hydration enthalpies of cationized glutamine and structural analogues in the gas phase. J. Am. Chem. Soc. 2005, 127, 10276-10286.

30. Lemoff, A. S.; Wu, C.-C.; Bush, M. F.; Williams, E. R. Binding energies of water to doubly hydrated cationized glutamine and structural analogues in the gas phase. J. Phys. Chem. A 2006, 110, 3662-3669.

31. Lemoff, A. S.; Bush, M. F.; O'Brien, J. T.; Williams, E. R. Structures of lithiated lysine and structural analogues in the gas phase: Effects of water and proton affinity on zwitterionic stability. J. Phys. Chem. A 2006, $110,8433-8442$

32. Ye, S. J.; Moision, R. M.; Armentrout, P. B. Sequential bond energies of water to sodium glycine cation. Int. J. Mass Spectrom. 2005, 240, 233-248.

33. Ye, S. J.; Moision, R. M.; Armentrout, P. B. Sequential bond energies of water to sodium proline cation. Int. J. Mass Spectrom. 2006, 253, 288-304.

34. Kamariotis, A.; Boyarkin, O. V.; Mercier, S. R.; Beck, R. D.; Bush, M. F. Williams, E. R.; Rizzo, T. R. Infrared spectroscopy of hydrated amino acids in the gas phase: Protonated and lithiated valine. J. Am. Chem. Soc 2006, 128, 905-916.

35. $\mathrm{Ai}, \mathrm{H} . ; \mathrm{Bu}, \mathrm{Y}$. Reservation energy bonds and structural stability of series of multi-hydrated $\left(\mathrm{n}_{\mathrm{H}_{2} \mathrm{O}}=1-10\right)$ glycine- $\mathrm{H}^{+} \mathrm{M}^{+}(\mathrm{M}=\mathrm{Li}, \mathrm{Na}$ or K) complexes. J. Phys. Chem. B 2000, 108, 1241-1254.

36. Remko, M.; Rode, B. M. Effect of metal ions $\left(\mathrm{Li}^{+}, \mathrm{Na}^{+}, \mathrm{K}^{+}, \mathrm{Mg}^{2+}, \mathrm{Ca}^{2+}\right.$ $\mathrm{Ni}^{2+}, \mathrm{Cu}^{2+}$, and $\mathrm{Zn}^{2+}$ ) and water coordination on the structure of glycine and zwitterionic glycine. J. Phys. Chem. A 2006, 110, 1960-1967.

37. Wincel, H. Hydration of gas-phase protonated alkylamines, amino acids, and dipeptides produced by electrospray. Int. J. Mass Spectrom. 2006, 251, 23-31.

38. Wincel, H. Hydration energies of protonated amino acids. Chem. Phys Lett. 2007, 439, 157-161.

39. Wincel, $\mathrm{H}$. Hydration energies of sodiated amino acids from gas-phase equilibria determinations. J. Phys. Chem. A 2007, 111, 5784-5791.

40. Dzidic, I.; Kebarle, P. Hydration of the alkali ions in the gas phase. Enthalpies and entropies of reactions $\mathrm{M}^{+}\left(\mathrm{H}_{2} \mathrm{O}\right)_{n-1}+\mathrm{H}_{2} \mathrm{O}=$ $\mathrm{M}^{+}\left(\mathrm{H}_{2} \mathrm{O}\right) n$. J. Phys. Chem. 1970, 74, 1466-1474.

41. Rodgers, M. T.; Armentrout, P. B. A thermodynamic "vocabulary" for metal ion interactions in biological systems. Acc. Chem. Res. 2004, 37, 989-998. 